\title{
ÓCULOS INTELIGENTE
}

\author{
V. H. F. Morales*, I. A. Pereira*, O. Y. Marin* e G. C. Araujo* \\ *Universidade Federal de Uberlândia, Uberlândia, Brasil \\ e-mail: victorh.morales00@gmail.com
}

\begin{abstract}
Resumo: A falta de acessibilidade aos portadores de deficiência é uma questão que tem preocupado a sociedade contemporânea. Deficientes visuais encontram limitações ao desempenhar diversas atividades cotidianas, desde um simples deslocamento por grandes centros urbanos e comerciais, a realização de tarefas domiciliares. Dessa forma, a necessidade de estudar e de desenvolver métodos que auxiliem este grupo de pessoas, minimizando os efeitos da deficiência, tem se tornado cada vez mais evidente.
\end{abstract}

Palavras-chave: Acessibilidade, deficiência visual, deslocamento.

\begin{abstract}
The lack of accessibility for disabled bearers is one of the issues which have concerned contemporary society. Visually impaired (blinded) people struggle in developing many daily activities, since moving by huge urban and commercial centers to performing household tasks. Therefore, it has increasingly been clear the need of studying and developing methods which may help this group of people by minimizing the effects of disability.
\end{abstract}

Keywords: Accessibility, visual impairment, moving.

\section{Introdução}

O termo deficiência visual refere-se a uma situação irreversível de diminuição da resposta visual em virtude de causas congênitas ou hereditárias, mesmo após tratamento clínico e/ou cirúrgico. Dessa forma, é definida como a perda total ou parcial, congênita ou adquirida da visão, sendo que o nível de acuidade visual pode variar desde leve, moderada, severa, profunda (que compõem o grupo de visão subnormal ou de baixa visão) até ausência total da resposta visual, cegueira. Segundo a OMS - Organização Mundial da Saúde (Bangkok, 1992) [1], o indivíduo com baixa visão ou visão subnormal é aquele que apresenta diminuição das suas respostas visuais, mesmo após tratamento e/ou correção óptica convencional, e uma acuidade visual menor que 6/18 à percepção de luz, ou um campo visual menor que 10 graus do seu ponto de fixação, mas que usa ou é potencialmente capaz de usar a visão para o planejamento e/ou execução de uma tarefa.

Ainda de acordo com a OMS, as principais causas de cegueira no Brasil são catarata, glaucoma, retinopatia diabética, cegueira infantil e degeneração macular. Segundo dados do IBGE de 2010 [2], no Brasil, mais de 6,5 milhões de pessoas têm alguma deficiência visual.
Desse total, 528.624 pessoas são incapazes de enxergar (cegos); 6.056 .654 pessoas possuem grande dificuldade permanente de enxergar (baixa visão ou visão subnormal); a cada 5 segundos 1 pessoa se torna cega no mundo; do total de casos de cegueira, $90 \%$ ocorrem nos países emergentes e subdesenvolvidos; e até 2020 o número de deficientes visuais poderá dobrar no mundo. Estatísticas como essas evidenciam ainda mais a necessidade de se desenvolver técnicas de auxílio à portadores de deficiência visual.

Uma forma de minimizar as dificuldades encontradas é através da utilização de tecnologias assistivas. Esses equipamentos visam proporcionar maior independência, qualidade de vida e inclusão social a pessoas debilitadas através da ampliação da comunicação, da mobilidade, do controle do ambiente, aprendizagem, trabalho e integração com a família, amigos e sociedade [3] [4].

Atualmente, pessoas com deficiência visual se locomovem com o auxílio de bengalas, permitindo-os obter maior noção do espaço físico ao redor e detectar diversos objetos, desde desnivelamentos na superfície do piso a obstáculos. No entanto, a bengala não detecta objetos altos, geralmente localizados acima da cintura, como placas de transito, orelhões, árvores, armários, entre outros fatores de risco que podem causar acidentes, visto que o usuário só ao identificaria após o choque [5] [6]. Dessa forma, torna-se evidente a importância de se utilizar equipamentos complementares a bengala para auxílio à deteç̧ão de objetos e obstáculos garantindo maior segurança e integridade a pessoas visualmente debilitadas.

Este trabalho apresenta como objetivo o desenvolvimento de um equipamento eletrônico de sensoriamento ultrassônico para ser utilizado por deficientes visuais na detecção de obstáculos posicionados em regiões acima do torax visando levar maior qualidade de vida à estes indivíduos.

\section{Materiais e métodos}

Hardware - Para o projeto, foi utilizado um Arduino Pro Mini, uma placa de circuito integrado contendo um núcleo microcontrolador ATmega328 responsável pela gerencia de comando do equipamento. Com um poder de processamento de $16 \mathrm{MHz}$ e dimensão pequena $(18 \mathrm{~mm} \times 33 \mathrm{~mm})$ [7], o Arduino Pro Mini mostrou ser uma placa de controle ideal para o projeto, característica comprovada durante a fase de testes. Demais 
componentes utilizados: resistores, cabos conectores, placa para soldagem de componentes eletrônicos, uma fonte de alimentação (bateria de 12 Volts), um sensor ultrassônico HC-SR04, um mini motor de vibração de celular, um óculos escuro entre outros materiais para montagem.

Inicialmente foi estudado o funcionamento do sensor HC-SR04, definindo os parâmetros de detecção e calculando os possíveis erros de medição. De acordo com o fabricante e com o manual do equipamento [8], além do HC-SR04 ser um sensor desenvolvido para comunicação com produtos Arduino, ele apresenta um alcance de sensoriamento dentro dos limites do projeto e possui dimensão baixa (45mm x 20mm x $15 \mathrm{~mm})$, tornando-se um componente ideal para o projeto.

Durante todo o planejamento, houve sempre uma grande preocupação com a liberdade de movimento do usuário, ou seja, o equipamento a ser desenvolvido não deveria impedir a execução de qualquer tipo de movimento livre desejado, como rotação, flexão ou extensão do pescoço e de outros membros do corpo durante, por exemplo, a locomoção. Esta prioridade foi um dos princípios que levaram à necessidade de utilizar um óculos como suporte para alocação do sensor ultrassônico e de todo o circuito eletrônico, garantindo um sensoriamento na altura da cabeça e restringindo todo o equipamento à um único local. De acordo com esboço, o equipamento desenvolvido recebeu o nome de Óculos Inteligente

Basicamente, a função do Óculos Inteligente é alertar o usuário, através de um feedback tátil [9], quando o mesmo se aproxima de um objeto posicionado acima da região torácica, evitando uma possível colisão. $\mathrm{O}$ feedback tátil é garantido com o uso de um mini motor, que vibra de acordo com a distância do usuário ao local de colisão. Para permitir que o usuário possa identificar a distância a qual o objeto detectado se encontra e possa tomar uma decisão, o motor de vibração somente é ligado em um dado limiar e seu poder de vibração [10] é alterado de forma inversamente proporsional ao aumento ou à diminuição da distância do usuário ao objeto. $\mathrm{O}$ diagrama de blocos apresentado na Figura 1 ilustra os processos do equipamento.

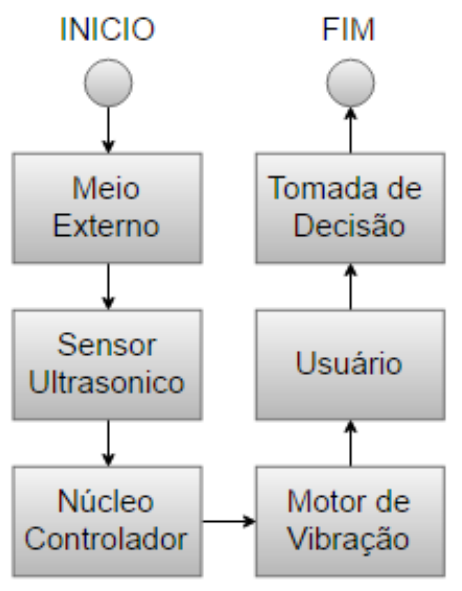

Figura 1: Diagrama de blocos do Óculos Inteligente.
Uma vez definido, testado e desenvolvido o hardware do equipamento, que segue demostrado na Figura 2, iniciou-se a fase de desenvolvimento do software.

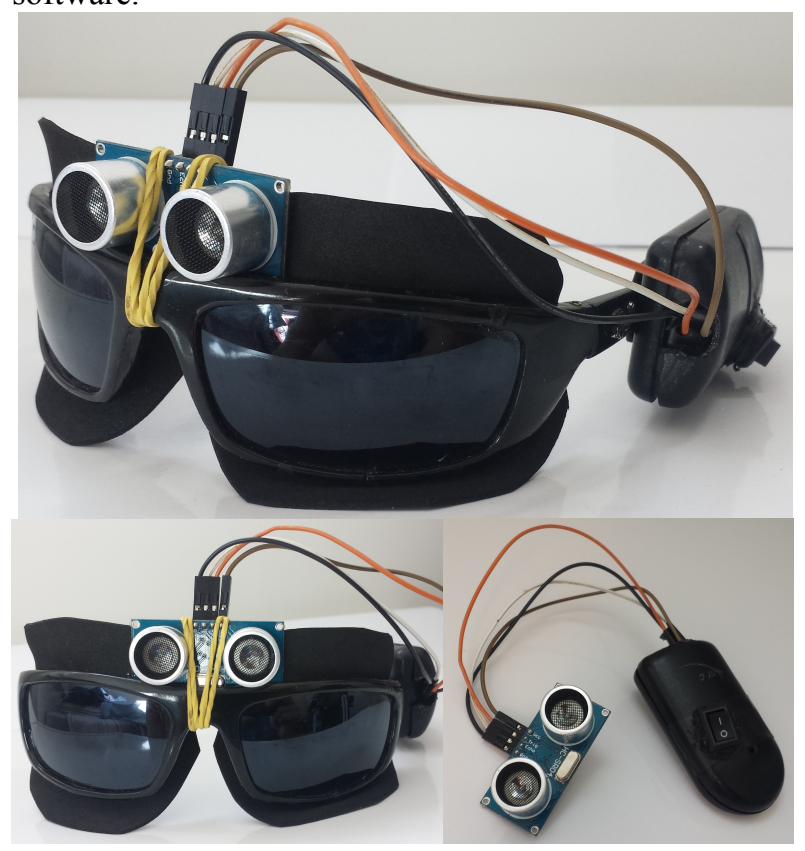

Figura 2: Fotos do Óculos Inteligente.

Software - O software foi elaborado na plataforma ARDUINO versão 1.6.9 utilizando a biblioteca NewPing.h para implementação do sensor ultrassônico. Através de vários testes feitos com a colaboração de voluntários não deficientes visuais, foi possível delimitar um limiar para se fazer o acionamento do mini motor de vibração. Para garantia de total obscuridade da visão, os voluntários foram devidamente vedados. De acordo com a média dos testes, foi definido que a 120 $\mathrm{cm}$ de distância do ponto de colisão, o motor deveria ser ligado onde a vibração se inicia com força de $20 \%$.

A alimentação do motor é feita por um sinal PWM. Possuindo 8 Bits, o Arduino Pro Mini permite uma excursão PWM de 0 a 255. Dessa forma, foi definido que a $120 \mathrm{~cm}$ o motor deveria vibrar com $20 \%$ de sua força $(P W M=50)$ e que a $15 \mathrm{~cm}$, na eminência de colisão, o motor deveria vibrar com uma força de $80 \%$ $(\mathrm{PWM}=200)$. No intervalo de $120 \mathrm{~cm}$ a $15 \mathrm{~cm}$, o poder de vibração do motor aumentaria inversamente proporcional à diminuição da distância do usuário ao ponto de colisão. Distância menores que $15 \mathrm{~cm}$ foram consideradas como colisão eminente, o motor de vibração permanece então desligado $(\mathrm{PWM}=0)$.

\section{Resultados}

Após a finalização do dispositivo, iniciou-se a etapa de testes finais com a participação dos membros da equipe desenvolvedora e com a colaboração de voluntários. De acordo com o questionário aplicado ao final dos testes, foi possível constatar que o dispositivo 
apresentou total eficiência na execução de sua funcionalidade, garantindo segurança e aumentado a confiabilidade durante o deslocamento (movimentação) de usuário com a visão obscurecida.

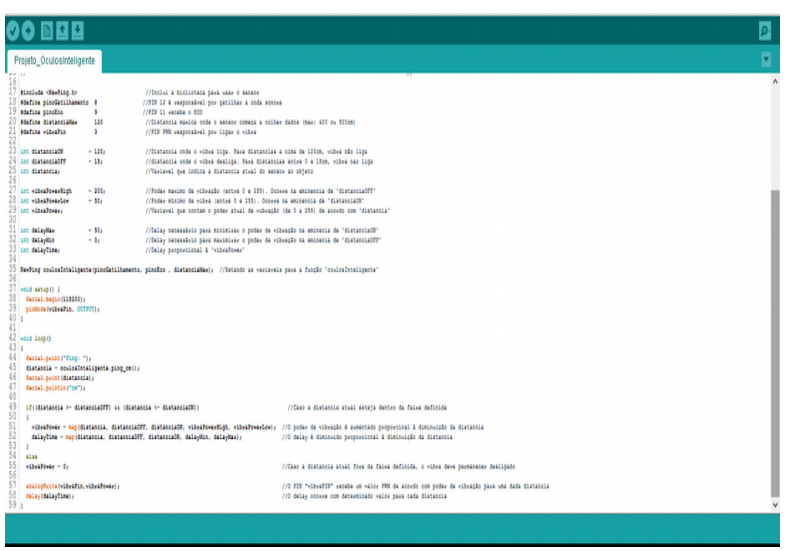

Figura 3: Imagem representativa do código de programação carregado no dispositivo.

\section{Discussão}

O equipamento é passível de melhoria. Atualmente, o grupo está estudando uma melhor maneira de fixar o sensor ultrassônico à haste central do óculos, de modo a permitir uma maior flexibilidade de alocação do dispositivo na haste, permitindo ao usuário opção de escolha do óculos a ser utilizado. Além disto, estudamse modos de isolar o equipamento de forma a torna-lo menos sensível à umidade.

A próxima etapa do projeto é fazer testes com voluntários portadores de deficiência visual, para constatação de total eficácia do dispositivo.

\section{Conclusão}

O Óculos Inteligente foi desenvolvido com o intuito de auxiliar deficientes visuais nas mais diversas tarefas diárias, alertando-os quando se aproximam de algum objeto localizado acima da região torácica, e que normalmente não são percebidos pela bengala, diminuindo a taxa de acidentes e contribuindo com a segurança e a integridade do usuário.

\section{Agradecimentos}

Toda a equipe do Óculos Inteligente agradece à orientação e supervisão do pHD. Adriano de Oliveira Andrade e, em especial, ao mestrando Luciano Brinck pelo o auxílio, comprometimento e ensinamentos durante todas as aulas da disciplina de Interface Homem-Máquina em Saúde do curso de Engenharia Biomédica ofertado pela Faculdade de Engenharia Elétrica (FEELT) da Universidade Federal de Uberlândia.

\section{Referências}

[1] Tipos e causas de Deficiência Visual. Portal da Oftalmologia: Um canal de informação, pesquisa e estudo da visão [internet]. Jun, 2004 [Citado em 12 Jun 2016]; disponível em: http://www.portaldaretina .com.br/home/saibamais.asp?cod=28\#.

[2] Deficiência Visual. Fundação Dorina Nowill para Cegos [internet]. [Citado em 12 Jun 2016]; disponível em: http:// www.fundacaodorina.org.br/ deficiencia-visual/.

[3] Inclusão de deficientes visuais: $\mathrm{O}$ uso da tecnologia assistiva em Redes Sociais e Online.- Robson A. Campêlo1, José Almir F. M. Júnior, Márcia M. Tabosa1, Ana H. Carneiro. [Citado em 12 Jun 2016]

[4] Sistema para Deficientes Visuais e Instrutores com redes Neurais e OCR. Instituto Federal de Educação, Ciencia e Tecnologia Triângulo Mineiro [internet]. Fev, 2013 [Citado em 12 Jun 2016]; disponível em: http://pt.slideshare.net/adilmar/sistema-ocr.

[5] Sensor Ultrassonico para Deficiente Visual. Kito [internet]. [Citado em 12 Jun 2016]; disponível em: http://sites.google.com/site/kitoeag/projetos/sensorultrassonico-para-deficiente-visual.

[6] Filho JSR, Cavalcante RV, Natacha A, Barros R. ARGOS - Auxílo à Locomoção de Deficientes Visuais a partir de pulseira Microcontroladas. Evento técnico-científico Computer on the Beach. 2011; 89-98.

[7] Arduino Pro Mini. Arduino LLC [internet]. [Citado em 12 Jun 2016]; disponível em: http:www.arduino. cc/en/Main/ArduinoBoardProMini.

[8] Sensor Ultrasonico HC-SR04. Cytron Technologies [internet]. Nov, 2013 [Citado em 12 Jun 2016]; disponível em: http://www.cytron.com.my/p-sn-hcsr04.

[9] What Is Tactile Feedback?. Ehow Discover [internet]. [Citado em 12 Jun 2016]; disponível em: www.ehow.com/facts_7557599_tactilefeedback.html.

[10] Shaftless Vibration Motor. Precision Microdrives [internet]. [Citado em 12 Jun 2016]; disponível em www.precisionmicrodrives.com. 